\title{
Extracellular Electron Transfer of Pseudomonas stutzeri Driven by Lithotrophic and Mixotrophic Denitrification
}

\section{Tetsuya YAMADA, ${ }^{a}$ Satoshi KAWAICHI, ${ }^{b}$ Akihisa MATSUYAMA, ${ }^{\mathrm{c}}$ Minoru YOSHIDA, ${ }^{\mathrm{c}}$ Nobuhiro MATSUSHITA, ${ }^{d}$ and Ryuhei NAKAMURA ${ }^{b, *}$}

a Department of Electronic Chemistry, Interdisciplinary Graduate School of Science and Engineering, Tokyo Institute of Technology, 4259 Midori, Nagatsuta, Yokohama 226-8503, Japan

b Biofunctional Catalyst Research Team, RIKEN Center for Sustainable Resource Science, 2-1 Hirosawa, Wako, Saitama 351-0198, Japan

c Chemical Genomics Research Group, RIKEN Center for Sustainable Resource Science, 2-1 Hirosawa, Wako, Saitama 351-0198, Japan

d Department of Chemistry and Materials Science, Graduate School of Science and Engineering, Tokyo Institute of Technology, 4259 Midori, Nagatsuta, Yokohama 226-8503, Japan

* Corresponding author: ryuhei.nakamura@riken.jp

\section{ABSTRACT}

The present study investigated extracellular electron transfer (EET) of Pseudomonas stutzeri, a model organism for bacterial denitrification. Electrochemical cultivation of $P$. stutzeri in a lithotrophic medium with $\mathrm{Fe}^{2+}$ ions generated the clear cathodic current associated with denitrification reactions. The EET ability of $P$. stutzeri was greatly strengthened by the addition of acetate, which correlated with the enhanced rate of the enzymatic oxidation of Fe ${ }^{2+}$. Since the addition of acetate induced the change of cellular metabolisms from lithotrophic denitrification to mixotrophic one, the present finding suggests the effectiveness of EET monitoring as a descriptor of bacterial denitrification activity and changing metabolisms according to the environmental conditions.

(c) The Electrochemical Society of Japan, All rights reserved.

Keywords : Extracellular Electron Transfer, Denitrification, Pseudomonas stutzeri

\section{Introduction}

Over the past century, human activity has increased the amount of fixed nitrogen $\left(\mathrm{NO}_{3}{ }^{-}, \mathrm{NO}_{2}{ }^{-}, \mathrm{NH}_{3}\right.$, etc.), which has led to the extensive eutrophication of fresh water and coastal zone, acid rain, and global warming. ${ }^{1}$ In particular, Haber-Bosch and fossil fuels combustion have been the major cause of those environmental problems, and their nitrogen fixation doubled the natural rate of terrestrial nitrogen fixation driven by microbial activity. ${ }^{2}$ Given that increasing human population would further disrupt the nitrogen cycle in nature, it is of utmost importance to restore and sustain the balance of nitrogen cycle. Considering the way to improve the situation, decreasing the use of fertilizer in agriculture and/or facilitating microbial denitrification processes to return the fixed nitrogen to nitrogen gas are the promising approach.

The denitrification process can be carried out by microorganisms which utilize $\mathrm{NO}_{3}{ }^{-}$and/or $\mathrm{NO}_{2}{ }^{-}$as terminal electron acceptors for cellular bioenergetics. ${ }^{3}$ During the process, several metalloproteins catalyze four successive steps of multielectron transfer reactions (Scheme 1). Demands for denitrification differ from the situations; for instance, the suppression of denitrification is required in agricultural lands, since its process competes with the uptake of $\mathrm{NO}_{3}{ }^{-}$by plants and thus results in the decreased efficiency of fertilizer. Contrary to this, enhancing microbial denitrification is an important target in the environments where extensive eutrophication is observed.

In an attempt to control the microbial denitrification depending on those different needs, we have focused on the ability of bacteria to gain and release electrons from/to electrodes during the course of cellular metabolisms: bacterial extracellular electron transfer (EET). Recent advance in the field of ElectroMicrobiology ${ }^{4}$ has expanded the concept of EET significantly not only to understand the microbial respiration with insoluble minerals, ${ }^{5}$ but also to control metabolic pathways and even gene-expression patterns. ${ }^{6}$ For instance, the
(A) ом 00000000000000000000000000000000010000 ом 000000000000000000000000000000000000

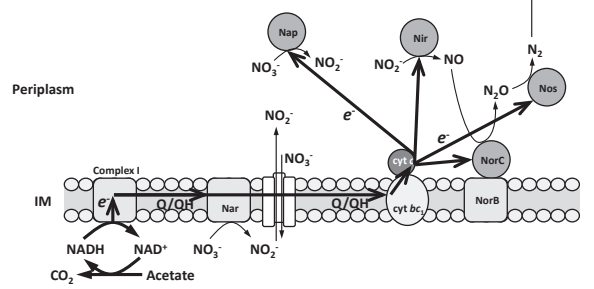

(B)

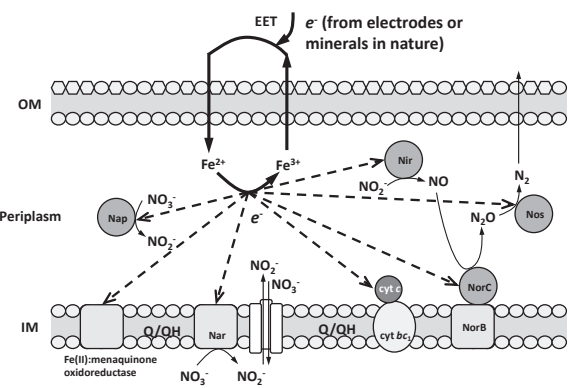

Scheme 1. Electron transfer models of denitrification pathway in P. stutzeri. (A) Organotrophic denitrification is driven by $\mathrm{NADH}$ from inside the cell as a primary electron donor. NADH generation is coupled to the oxidation of acetate. (B) Lithotrophic denitrification utilizes $\mathrm{Fe}^{2+}$ from outside the cell. Dotted arrows indicate the hypothetical electron flow. Both pathways comprise respiratory nitrate reductase (Nar), nitrite reductase (Nir), NO reductase (NorBC), and $\mathrm{N}_{2} \mathrm{O}$ reductase (Nos). Furthermore, a periplasmic nitrate reductase (Nap) and the postulated nitrate/nitrite antiporter at the inner membrane have been included in the models. 
activity of TCA cycle and gene expression of Shewanella cells were regulated by changing electrode potential. ${ }^{6}$ It was also demonstrated that even cyanobacteria, which lack the ability to conduct EET, could sense the electrode potential by using artificial redox mediators, and the redox state of plastoquinone and consequently the circadian clock was regulated by electrode potential. ${ }^{7}$ These studies have encouraged us to hypothesize that the microbial denitrification activity can be regulated by optimizing environmental redox states. ${ }^{8,9}$

As a first step toward controlling bacterial denitrification, the present study investigated the EET ability of Pseudomonas stutzeri, a model organism for the study of bacterial denitrification. P. stutzeri is characterized as its diverse and versatile bioenergetics for denitrification. It can utilize either organics, inorganics such as $\mathrm{Fe}^{2+}$, or both of them as an electron source for denitrification, $, 30,11$ which allows them to flexibly change the cellular metabolisms among organotrophic, lithotrophic, and mixotrophic denitrification according to environmental conditions. Here we report the in-vivo monitoring of EET coupled with denitrification by P. stutzeri, and demonstrate how the EET efficiency is affected by changing the culture media from lithotrophic to mixotrophic conditions.

\section{Experimental}

Cell Preparation: P. stutzeri (JCM5965) was provided by Japan Collection of Microorganisms, RIKEN BRC which participates in the National BioResource Project of the MEXT, Japan. Cells were cultured in autoclaved Lysogeny Broth medium (LB broth) and incubated aerobically with shaking at $25^{\circ} \mathrm{C}$. Subsequently, the culture was centrifuged at $6270 \mathrm{rpm}$ for $5 \mathrm{~min}$, and the pelleted cell was washed with a fresh PS medium $\left(10 \mathrm{mM} \mathrm{NH}_{4} \mathrm{Cl}, 1 \mathrm{mM} \mathrm{MgCl}_{2}\right.$, $0.5 \mathrm{mM} \mathrm{CaCl}_{2}, 5 \mathrm{mM} \mathrm{NaHCO}_{3}, 10 \mathrm{mM}$ HEPES). This process was repeated 3 times.

Product Analysis: P. stutzeri was incubated in a deaerated PS medium with Ar gas. We also used the modified PS mediums of which $\mathrm{pH}$ buffer was replaced by $\mathrm{NaHPO}_{4}$ and $\mathrm{KH}_{2} \mathrm{PO}_{4}$. The amount of $\mathrm{N}_{2}$ production was measured by $\mathrm{GC}$ equipped with a TCD detector (GC-8A, Shimadzu). Hach kits (method no. 8192, 8507 and 8155) were used for the quantification of $\mathrm{NO}_{3}{ }^{-}, \mathrm{NO}_{2}{ }^{-}$and $\mathrm{NH}_{4}{ }^{+}$. For the detection of $\mathrm{NH}_{4}{ }^{+}$, the cells were incubated in the modified PS medium which lacks $\mathrm{NH}_{4} \mathrm{Cl}$.

Electrochemical measurements: A single-chamber, three-electrode system was used for the electrochemical studies of intact cells. ${ }^{12} \mathrm{~A}$ tin-doped $\operatorname{In}_{2} \mathrm{O}_{3}$ (ITO) substrate (surface area of $3.1 \mathrm{~cm}^{2}$ ) was used as a working electrode and was placed at the bottom of the reactor. $\mathrm{Ag} /$ $\mathrm{AgCl}(\mathrm{KCl}$ saturated) and a platinum wire were used as reference and counter electrodes, respectively. Five milliliters of DM containing $1 \mathrm{mM} \mathrm{MgCl}_{2}, 0.5 \mathrm{mM} \mathrm{CaCl}_{2}, 5 \mathrm{mM} \mathrm{NaHCO}_{3}, 10 \mathrm{mM} \mathrm{NaHPO}_{4}$, and $1.76 \mathrm{mM} \mathrm{KH}_{2} \mathrm{PO}_{4}$ was added into the electrochemical cell as an electrolyte and was deaerated by bubbling with $\mathrm{N}_{2}$ for $5 \mathrm{~min}$. After that, $\mathrm{N}_{2}$ was flowed into the head space during the measurement.

\section{Results and Discussion}

Organotrophic denitrification in the cellular metabolism of $P$. stutzeri has been extensively studied, and a pathway for electron transport spanning from their inner membrane (IM) to the periplasmic space has been proposed in the previous studies (Scheme 1A). ${ }^{13}$ During organotrophic denitrification, organic compounds such as acetate act as the primary electron source for NADH generation. In the process, metalloproteins involved in $\mathrm{NO}_{3}{ }^{-}$reduction and the subsequent steps of denitrification are located in both sides of the IM. Besides the membrane bound nitrate reductase (Nar), P. stutzeri has another $\mathrm{NO}_{3}{ }^{-}$reductase (Nap) which is located in the periplasm. In addition to cytoplasmic NADH as the primary electron donor for the overall reaction, ubiquinol $(\mathrm{QH})$ and periplasmic $c$-type cytochromes are predicted to serve as electron donors for Nar and the other

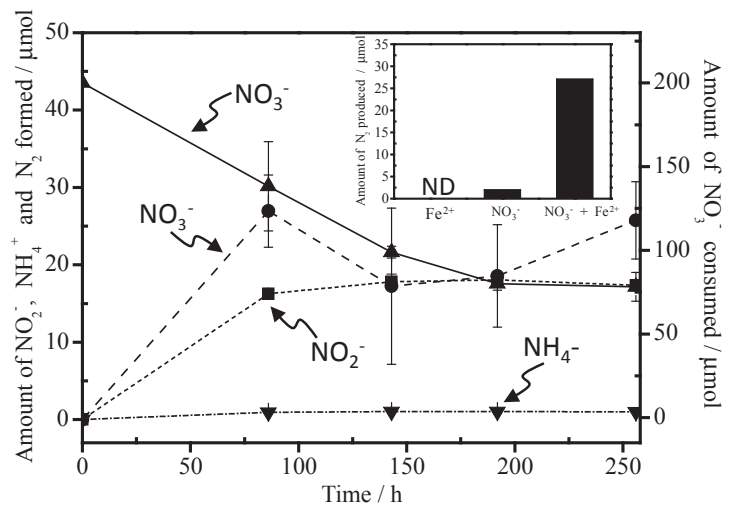

Figure 1. Time course of $\mathrm{N}$-products and $\mathrm{NO}_{3}{ }^{-}$consumption by P. stutzeri in medium containing $5 \mathrm{mM} \mathrm{NaNO}_{3}$ and $\mathrm{FeSO}_{4}$. Initial $\mathrm{OD}_{600}$ was 0.9 . Inset: $\mathrm{N}_{2}$ production by $P$. stutzeri for $162 \mathrm{~h}$ from medium containing $5 \mathrm{mM}$ of $\mathrm{NaNO}_{3}$ and $\mathrm{FeSO}_{4}$, and abiotic control with $5 \mathrm{mM} \mathrm{NaNO}_{3}$ and $5 \mathrm{mM} \mathrm{FeSO}_{4}$.

periplasmic enzymes, respectively. ${ }^{13}$ Although it is also reported that $P$. stutzeri can perform lithotrophic denitrification reactions using extracellular $\mathrm{Fe}^{2+},{ }^{10,11}$ it has been unknown how the electron flow from $\mathrm{Fe}^{2+}$ drives denitrification, and also whether complete denitrification can be possible or not (Scheme 1B). To get insight into those questions, we firstly cultivated $P$. stutzeri in batch cultures and analyzed the products of lithotrophic denitrification.

The time course of the products from the cell culture cultivated with $\mathrm{Fe}^{2+}$ is shown in Fig. 1. No organic compounds were added in the reactor as an electron donor. With increased cultivation time, both $\mathrm{N}_{2}$ and $\mathrm{NO}_{2}{ }^{-}$increased, which correlated with the consumption of $\mathrm{NO}_{3}{ }^{-}$and a small increase of $\mathrm{NH}_{4}{ }^{+}$. The total amount of electrons consumed by the production of $\mathrm{NO}_{2}{ }^{-}$and $\mathrm{N}_{2}$ after $260 \mathrm{~h}$ of cultivation was $\sim 290 \mu \mathrm{mol}$, which was higher than the amount of $\mathrm{Fe}^{2+}$ added in the cell culture $(200 \mu \mathrm{mol})$. Since this imbalance of stoichiometry is reproducible, we consider that organics accumulated inside the cells during preculture with LB and/or cell lysis provided surplus electrons for denitrification. ${ }^{14,15}$ The control experiments with the cell cultures lacking either $\mathrm{NO}_{3}{ }^{-}$or $\mathrm{Fe}^{2+}$ generated less amount of $\mathrm{N}_{2}$ (inset of Fig. 1). In addition, after cultivation of the cells in the presence of $\mathrm{NO}_{3}{ }^{-}$and $\mathrm{Fe}^{2+}$, the colorless cell suspension turned brown, indicating the formation of $\mathrm{Fe}^{3+}$ precipitates. These results indicate that the electron from $\mathrm{Fe}^{2+}$ is injected to either Nap or Nar and delivered to the terminal periplasmic protein responsible for the reduction of $\mathrm{N}_{2} \mathrm{O}$ to $\mathrm{N}_{2}$ (Nos, see Scheme 1B). We could not confirm the clear cell growth of the cell under a lithotrophic culture condition, which is consistence with the previous report ${ }^{11}$ and suggests that lithotrophic denitrification could not produce NADH. It is therefore reasonable to conclude the bioenergetics for lithotrophic denitrification differ from those for organotrophic one.

To monitor EET driven by denitrification in vivo, we electrochemically cultured the cells using an electrode of ITO substrate poised at $-0.2 \mathrm{~V}$ (vs. $\mathrm{Ag} / \mathrm{AgCl} \mathrm{KCl}$ sat.) as a working electrode. No organic compounds were added in the reactor as an electron donor. As shown in trace 2 in Fig. 2A, almost no microbial current generation (Current density was less than $-0.004 \mu \mathrm{A} \mathrm{cm}^{-2}$ ) was observed in the absence of $\mathrm{Fe}^{2+}$ ions. However, weak, but clear cathodic current was generated immediately after adding $\mathrm{Fe}^{2+}$ ions and reached a constant value of approximately $-0.01 \mu \mathrm{Acm}^{-2}$, which was then decreased gradually with increasing cultivation time (trace 1, Fig. 2). Cathodic current generation can be ascribed to the EET from an electrode to inside a cell driven by lithotrophic denitrification, as no cathodic current was generated for the reactor which lacks the bacterial cells (data not shown).

From protein sequence analysis of $P$. stutzeri using PSORTb version 3.0.2 ${ }^{16}$ which indicates that none of the 47 heme proteins 


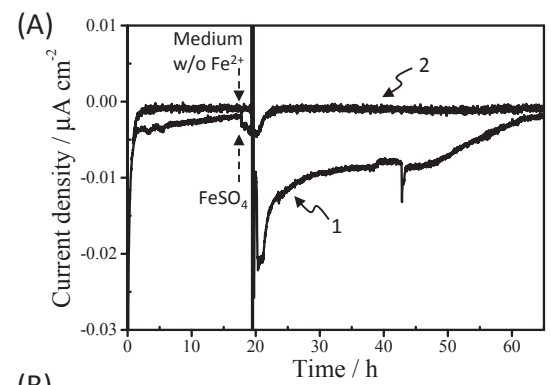

(B)

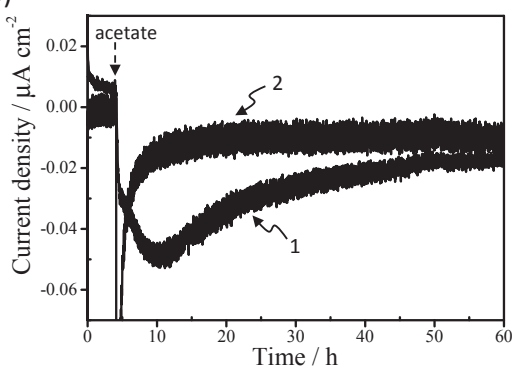

Figure 2. (A) Effects adding $\mathrm{FeSO}_{4}$ on the microbial current generation for $P$. stutzeri at an electrode potential of $-0.2 \mathrm{~V}$ (vs. $\mathrm{Ag}$ / $\mathrm{AgCl} \mathrm{KCl}$ sat.). $\mathrm{FeSO}_{4}$ solution was added to a reactor at a final concentration of $5 \mathrm{mM}$ at the time point indicated with dotted arrow (trace 1). Medium lacking $\mathrm{FeSO}_{4}$ was also added as a control experiment (trace 2). (B) Effects of adding acetate on the microbial current generation for $P$. stutzeri with (trace 1) and without $\mathrm{Fe}^{2+}$ (trace 2) at an electrode potential of $-0.2 \mathrm{~V}$ (vs. $\mathrm{Ag} / \mathrm{AgCl} \mathrm{KCl}$ sat.). Acetate solution was added to a reactor at a final concentration of $21 \mathrm{mM}$ at the time point indicated with dotted arrow.

locates on the outer membrane $(\mathrm{OM})$, the cathodic current generation by $P$. stutzeri (trace 1, Fig. 2A) is likely to be driven by electron shuttling processes between periplasmic and/or IM bound metalloproteins and an electrode (Scheme 1B). The lack of OM cytochromes is in harmony with the inability of $P$. stutzeri to extract electron directly from an electrode (trace 2, Fig. 2), and this aspect is in sharp contrast with Fe-oxidizing bacteria such as Acidithiobacillus ferrooxidans ${ }^{17}$ and Mariprofundus ferrooxidans ${ }^{18}$ which exploits OM cytochromes as the primal conduit for EET to/from electrodes.

To investigate if the metabolic change from lithotrophy to mixotrophy affects the EET or not, we added acetate to the electrochemical reactor. P. stutzeri utilizes acetate as a primary electron source for the generation of NADH in cytoplasmic space and as an electron donor for a complete denitrification reaction (Scheme 1A). Hence, we can anticipate that the addition of acetate generates the electron flow from inside a cell to an electrode (i.e. revise electron flow to lithotrophy), resulting in the effective suppression of microbial cathodic current generation, or even the generation of anodic current like bacterial EET for Shewanella and Geobacter species.

Figure 2B shows the effect on microbial current generation by adding acetate to the cells of $P$. stutzeri. In this experiment, prior to the addition of acetate, the cells were cultured in the electrochemical reactor in advance. One reactor contains both $\mathrm{NO}_{3}{ }^{-}$and $\mathrm{Fe}^{2+}$, and the other contains $\mathrm{NO}_{3}{ }^{-}$alone (trace 1 and 2, respectively). After microbial current being diminished, acetate was supplemented to the reactors at the time indicated by dotted arrows (Fig. 2B). Contrary to our expectation, the addition of acetate greatly facilitated the cathodic current generation and maintained it for approximately $40 \mathrm{~h}$ (trace 1, Fig. 2B). It was also found that such a sustained current enhancement was not observed for the cell culture that lacks $\mathrm{Fe}^{2+}$ ions after adding acetate (trace 2, Fig. 2B).

Considering the fact that $P$. stutzeri is incapable of conducting EET without $\mathrm{Fe}^{2+}$ ions (trace 2, Fig. 2A), the enhanced cathodic current is a consequence of the increased rate of $\mathrm{Fe}^{2+}$ oxidation, ${ }^{10,15}$ which is driven by the change of metabolisms from lithotrophy to mixotrophy (i.e. addition of acetate in an electrochemical reactor). It is worth noting here that lithotrophic and mixotrophic denitrification share the same intermediates of $\mathrm{NO}_{2}{ }^{-}, \mathrm{NO}$ and $\mathrm{N}_{2} \mathrm{O}$ in the periplasm (Scheme 1). Since they are redox-active species and can act both as an electron donor and an acceptor, we speculate that the unexpected effects of acetate on the direction of EET is likely due to the formation of those redox-active intermediates. That is to say, acetate addition can accelerate the oxidation of $\mathrm{Fe}^{2+}$ (i.e. facilitate cathodic EET, see Scheme 1B), ${ }^{10,15}$ if we assume that acetate addition enhances the production rate of one of those intermediates via organotrophic electron transfer pathways (i.e. electron injection from NADH), of which production processes are associated with the rate determining step of lithotrophic denitrification with $\mathrm{Fe}^{2+}$.

In summary, we have demonstrated the ability of $P$. stutzeri to convert $\mathrm{NO}_{3}{ }^{-}$to $\mathrm{N}_{2}$ in a lithotrophic medium using $\mathrm{Fe}^{2+}$ as an electron source. It was also demonstrated that the cathodic EET ability of $P$. stutzeri was strengthen by the addition of acetate, which correlated with the switching cellular metabolisms from lithotrophic to mixotrophic denitrification. Further research is needed to elucidate the mechanism of enhanced EET by acetate. To this end, we will apply chemical inhibitor experiments using Antimycin A, Malonic acid, Quinacrine, Dicumarol, and Rotenone, as these chemicals possibly have the ability to differentiate the EET pathways operated in lithotrophic and mixotrophic denitrification. ${ }^{19}$ We also anticipate that the kinetic isotope experiments with ${ }^{15} \mathrm{NO}_{3}{ }^{-}$ coupled with in-vivo monitoring of EET will afford to probe the complex electron flow associated with the diverse and versatile bioenergetics for denitrification. Those studies will provide the important foundation toward the regulation of microbial denitrification via environmental redox tuning.

\section{Acknowledgment}

This work was financially supported by a Grant-in-Aid for Specially Promoted Research from the Japan Society for Promotion of Science (JSPS) KAKENHI Grant Number 24000010.

\section{References}

1. M. Duca and M. T. M. Koper, Energy Environ. Sci., 5, 9726 (2012).

2. D. E. Canfield, A. N. Glazer, and P. G. Falkowski, Science, 330, 192 (2010).

3. J. Lalucat, A. Bennasar, R. Bosch, E. García-Valdés, and N. J. Palleroni, Microbiol. Mol. Biol. Rev., 70, 510 (2006)

4. D. R. Lovley, Annu. Rev. Microbiol., 66, 391 (2012).

5. D. R. Lovley, Microbiol. Rev., 55, 259 (1991).

6. S. Matsuda, H. Liu, A. Kouzuma, K. Watanabe, K. Hashimoto, and S. Nakanishi, PLOS ONE, 8, e72901 (2013)

7. Y. Lu, K. Nishio, S. Matsuda, Y. Toshima, H. Ito, T. Konno, K. Ishihara, S. Kato, K. Hashimoto, and S. Nakanishi, Angew. Chem., Int. Ed., 53, 2208 (2014).

8. A. R. Rowe, P. Chellamuthu, B. Lam, A. Okamoto, and K. H. Nealson, Front. Microbiol., 5, 784 (2015).

9. A. Vilar-Sanz, S. Puig, A. García-Lledó, R. Trias, M. D. Balaguer, J. Colprim, and L. Bañeras, PLOS ONE, 8, e63460 (2013).

10. E. M. Muehe, S. Gerhardt, B. Schink, and A. Kappler, FEMS Microbiol. Ecol., 70, 335 (2009).

11. K. L. Straub, M. Benz, B. Schink, and F. Widdel, Appl. Environ. Microbiol., 62, 1458 (1996)

12. A. Okamoto, K. Hashimoto, K. H. Nealson, and R. Nakamura, Proc. Natl. Acad. Sci. U.S.A., 110, 7856 (2013).

13. W. G. Zumft, Microbiol. Mol. Biol. Rev., 61, 533 (1997).

14. K. A. Weber, F. W. Picardal, and E. E. Roden, Environ. Sci. Technol., 35, 1644 (2001).

15. M. Benz, A. Brune, and B. Schink, Arch. Microbiol., 169, 159 (1998).

16. N. Y. Yu, J. R. Wagner, M. R. Laird, G. Melli, S. Rey, R. Lo, P. Dao, S. C. Sahinalp, M. Ester, L. J. Foster, and F. S. L. Brinkman, Bioinformatics, 26, 1608 (2010).

17. T. Ishii, S. Kawaichi, H. Nakagawa, K. Hashimoto, and R. Nakamura, Front. Microbiol., 6, 994 (2015).

18. T. Mogi, T. Ishii, K. Hashimoto, and R. Nakamura, Chem. Commun., 49, 3967 (2013).

19. L. Yu, Y. Yuan, S. Chen, L. Zhuang, and S. Zhou, Electrochem. Commun., 60, 126 (2015). 